\title{
Estudo teórico da adsorção de metanol, etanol, 1-propanol e 1-butanol em zeólitas H-ZSM-5
}

\author{
*Rogério J. Costa1 (PG), Elton A. S. Castro²(PQ), João B. L. Martins ${ }^{1}(\mathrm{PQ})$. \\ rogerquim@gmail.com \\ ${ }^{1}$ Universidade de Brasília \\ ${ }^{2}$ Universidade Estadual de Goiás
}

\section{RESUMO}

O estudo das reações químicas de superfícies tem se mostrado de interesse para muitas áreas da ciência, indústria, saúde pública, meio ambiente e busca de fontes de energia alternativa. A reatividade pode ser compreendida no processo de adsorção envolvendo adsorventes e adsorbatos, adicionados no uso de catalisadores seletivos. Moléculas de álcoois lineares como metanol, etanol, 1-propanol e 1-butanol podem ser convertidas em outros produtos, de maior valor, quando adsorvidas nas cavidades materiais porosos, com os da zeólita H-ZSM-5. Neste trabalho teórico cálculos mecânico-quânticos foram realizados com modelos envolvendo as interações destes quatro álcoois em um poro específico da $\mathrm{H}$ ZSM-5 em que propriedades eletrônicas e estruturais destas interações foram avaliadas.

Palavras-chave: Adsorção. H-ZSM-5. Álcoois. Cálculos computacionais.

\section{Introdução}

O estudo das reações químicas de superfícies envolvendo diferentes fases de agregação é assunto de grande interesse na área da ciência dos materiais por desempenhar papeis importantes em operações industriais e aprimoramento de tecnologias, ou manutenção do meio ambiente com destaque na produção de energia através de fontes renováveis ${ }^{1}$. A seletividade de moléculas em misturas heterogêneas pode ser alcançada com maior rapidez e eficiência pelo uso de catalisadores seletivos. ${ }^{2,3}$

A produção de hidrocarbonetos tem sido bastante explorada pelo uso de zeólitas, um tipo de catalisador ácido formado por átomos de alumínio, silício e oxigênio em estruturas altamente porosas com íons como sódio $\left(\mathrm{Na}^{+}\right)$, potássio $\left(\mathrm{K}^{+}\right)$, cálcio $\left(\mathrm{Ca}^{2+}\right)$, magnésio $\left(\mathrm{Mg}^{2+}\right)$ presentes na rede. Mais de uma centena de zeólitas estão catalogadas obtidas naturalmente e artificialmente, como a H-ZSM-5 (Zeolite Socony Mobil Five) que apresenta ampla aplicação na síntese de derivados de petróleo. ${ }^{5} \mathrm{~A}$ adsorção dos álcoois lineares metanol, etanol, 1-propanol e 1-butanol em um dos poros da H-ZSM-5 foi estudada neste trabalho através de cálculos computacionais, utilizando métodos semi-empíricos e ab initio.

\section{Metodologia}

Foram utilizados métodos UFF, PM6 e DFT, com os funcionais B3LYP, M062X e $\omega B 97 X D$, com auxílio da função de base $6-31+\mathrm{G}(\mathrm{d})$, aplicados em conjunto no método híbrido ONIOM (Our own Nlayered Integrated molecular Orbital and molecular Mechanics). Este é um método sofisticado que possui como uma das principais características a possibilidade de trabalhar-se com sistemas relativamente grandes utilizando diferentes métodos de teorias em diferentes locais da estrutura. A otimização visou o relaxamento da cavidade larga da H-ZSM-5 (Figura 1-a) onde se encontra o sítio ácido (Figura 1-b) de forma progressiva através da inclusão de 
tetraedros de silicatos $\left(\mathrm{SiO}_{4}\right)$ nas camadas altas de teorias até o completo fechamento da circunferência do poro, composto por dez tetraedros (Figura 1-c), com o objetivo de encontrar o menor número de tetraedros que fosse representativo do conjunto total.

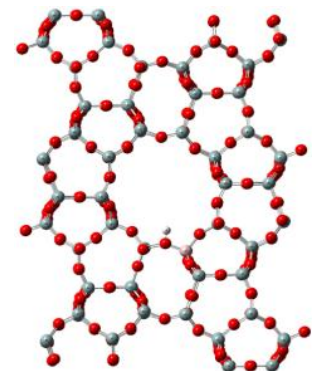

(a)

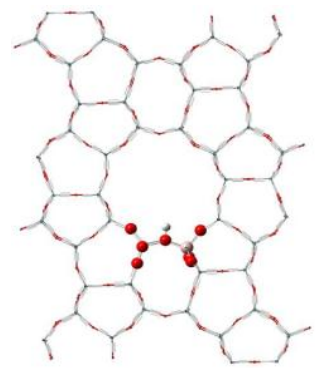

(b)

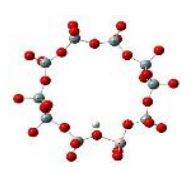

(c)

Figura 1. Modelo de H-ZSM-5 (a) e destaque para o sítio ácido (b) e a circunferência do poro (c)

\section{Resultados e Discussão}

As energias de ligações foram calculadas através das diferenças das energias totais dos complexos otimizados e suas respectivas partes isoladas e otimizadas dispostas para os grupos de modelos calculados com ONIOM, bem como as Energias de Adsorções calculadas após o processo de otimização. A energia de interação e a energia de ligação em conjunto com as contribuições destas energias foram avaliadas, seguindo métodos descritos na literatura. Distâncias, ângulos e outras informações de geometrias também foram analisadas.

\section{Considerações Finais}

Os níveis teóricos utilizados para os cálculos dos complexos de H-ZSM5/Álcoois na cavidade mais larga tem se mostrado eficientes com resultados de geometrias e energias próximos de outros trabalhos teóricos e experimentais, onde o métodos ONIOM vem mostrando tendências de aumento de energias de ligação com o aumento de tetraedros liberados e tamanho do adsorbato. As distâncias $\mathrm{OH}$ dos sítios ácidos das zeólitas aumentaram com o aumento dos tetraedros otimizados com o método PM6:UFF, não persistindo com o aumento das cadeias de álcoois, o mesmo apresentado pelo método B3LYP:UFF.

\section{Agradecimentos}

FAPDF, CNPq, CAPES

\section{Referências}

[1] M. Bjørgen, F. Joensen, M. S. Holm, U. Olsbye, K.-P. Lillerud, and S. Svelle. Applied Catalysis A: General, vol. 345, no. 1, pp. 43-50, 2008.

[2] D. Bryant and W. Kranich. Journal of catalysis, vol. 8, no. 1, pp. 8-13, 1967.

[3] K. Tanabe and W. F. Hölderich. Applied Catalysis A: General, vol. 181, no. 2, pp. 399-434, 1999.

[4] A. Takahashi, W. Xia, Q. Wu, T. Furukawa, I. Nakamura, H. Shimada, and T. Fujitani. Applied Catalysis A: General, vol. 467, pp. 380-385, 2013.

[5] X. Zhang, R. Wang, X. Yang, and F. Zhang. Microporous and Mesoporous Materials, vol. 116, no. 1, pp. 210-215, 2008. 